\title{
Hereditary haemorrhagic telangiectasia: a clinical analysis
}

\author{
M E M Porteous, J Burn, S J Proctor
}

\begin{abstract}
Data from 98 patients with hereditary haemorrhagic telangiectasia (HHT) are presented. All were symptomatic by 40 years of age and $62 \%$ by 16 years. Nose bleeding was the first symptom of disease in $90 \%$ of cases with mucocutaneous telangiectases appearing 5 to 20 years later. Complications of HHT are discussed and an age of onset curve given.
\end{abstract}

Hereditary haemorrhagic telangiectasia (HHT) is an autosomal dominant disorder of vascular proliferation characterised by mucocutaneous telangiectases and epistaxes. The term HHT was suggested in 1909 by Hanes, ${ }^{1}$ although the disease had previously been described by Sutton, ${ }^{2}$ Rendu, ${ }^{3}$ Osler, ${ }^{4}$ and Weber. ${ }^{5}$ HHT has been well documented in most ethnic groups. ${ }^{67}$ With careful clinical examination of subjects at risk, non-penetrance is rare. ${ }^{89}$ The homozygous state appears to be lethal, ${ }^{10}$ although there are few such published cases.

The usual presenting feature is epistaxis from telangiectases over the nasal septum and inferior turbinate beginning around puberty. ${ }^{11}$ The characteristic cutaneous telangiectases appear much later and their absence does not preclude the diagnosis. Most authors suggest that a diagnosis of HHT can be made with confidence if two of the following features are present; a positive family history, mucocutaneous telangiectases, and epistaxes.

Larger vessel involvement is common. Pulmonary arteriovenous malformations (PAVM) are found in approximately 15 to $20 \%$ of patients ${ }^{12}$ and can lead to embolic complications or high output cardiac failure. AVMs also occur in the cerebral and hepatic vessels although less frequently. Though well recognised as a source of clinical subjects for student medical examinations, HHT families have attracted relatively little interest from the genetic viewpoint or from the perspective of long term morbidity and mortality. We present clinical data from a series of 98 patients with HHT from 35 families ascertained throughout Britain.

\section{Materials and methods}

Ethical approval for the clinical study was given by the Newcastle District Ethical Com- mittee and the help of the National Self Help group for HHT sufferers solicited. The members of the self help group were sent an invitation to participate in research aimed at delineating the clinical spectrum of HHT further. One of the authors (MP) visited families in their own home to document features of HHT and take blood samples for DNA analysis. In all cases, family members were subjected to limited medical examination.

An attempt at more complete ascertainment in the Northern Region involved circulating all the general practitioners, ENT surgeons, and haematologists with a request for patients' names. The patients were then invited to take part in the study. A total of 35 families was ascertained nationwide and 98 affected subjects assessed.

\section{Results}

PREVALENCE

All general practitioners, ENT surgeons, and haematologists in the Northern Region of England (population 3.1 million) were circulated with a request for details of patients over the age of 16 years with HHT under their care on 1 March 1990. A total of $316 / 1060 \mathrm{GPs}, 7 / 22$ ENT surgeons, and 12/18 haematologists returned the questionnaire. Seventy-nine patients were identified giving a minimum point prevalence on 1 March 1990 of 1 in 39216.

\section{AGE OF ONSET}

Patients were asked to describe the presenting feature of their disease; 88/98 reported epistaxes, five visible telangiectases, and two gastrointestinal bleeding. Two patients were diagnosed when routine chest radiographs showed PAVMs (fig 1). One subject presented with an epileptic fit at the age of 6 years and was shown to have a cerebral arteriovenous malformation on cranial CT scan (fig 2).

The age at which the patient first became symptomatic is plotted as a cumulative frequency in fig 3. Where an approximate age of onset was given, the latest age of onset was plotted. There were $62 \%$ who were symptomatic by the age of $16,83 \%$ by 26 years, and $97 \%$ by 35 years. All the patients in our series showed evidence of the disease by the age of 40 . In one family, an affected grandfather and grandson were separated by an apparently nor- 


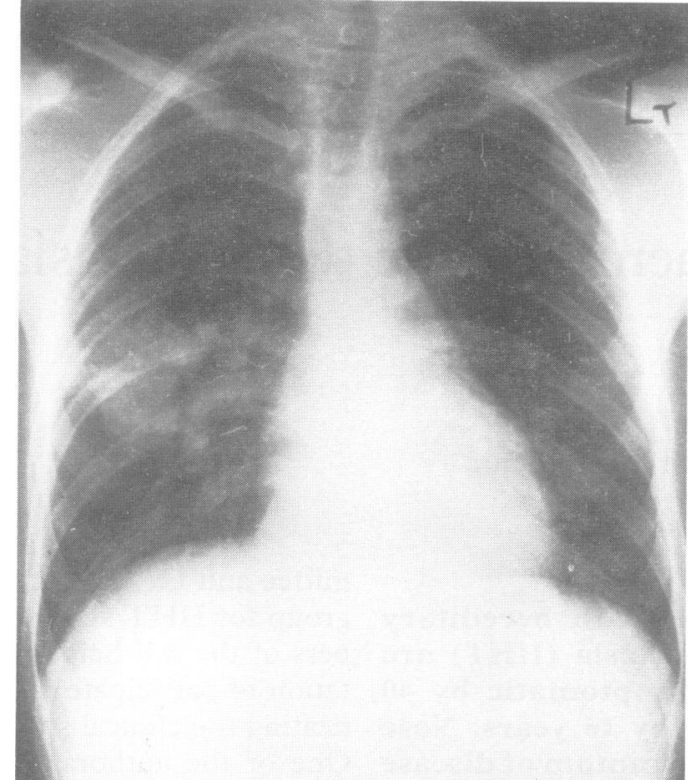

Figure 1 Plain chest radiograph showing large $P A V M$.

mal father. This subject was 22 years of age at the time of examination and cannot be regarded as an example of non-penetrance at this age.

\section{CLINICAL FEATURES}

Epistaxis

Of the 40 patients in the study over 50 years old, 16 reported that the epistaxes had increased in frequency, duration, and severity with age, 16 noticed no particular change, and eight noted an improvement. Neither nostril was preferentially involved. Cautery of nasal lesions produced a temporary improvement but this was only sustained in one case. Several patients felt that their condition deteriorated within six months of cauterisation.

\section{Cutaneous telangiectases}

Mucocutaneous telangiectases tended to appear between five and 20 years after the epistaxes in the majority of patients. The commonest sites for the lesions were the palms and nailbeds $(71 \%)$, the lips and tongue $(66 \%$, fig 4 ), and the face $(20 \%)$. The lesions tend to become more numerous with age.
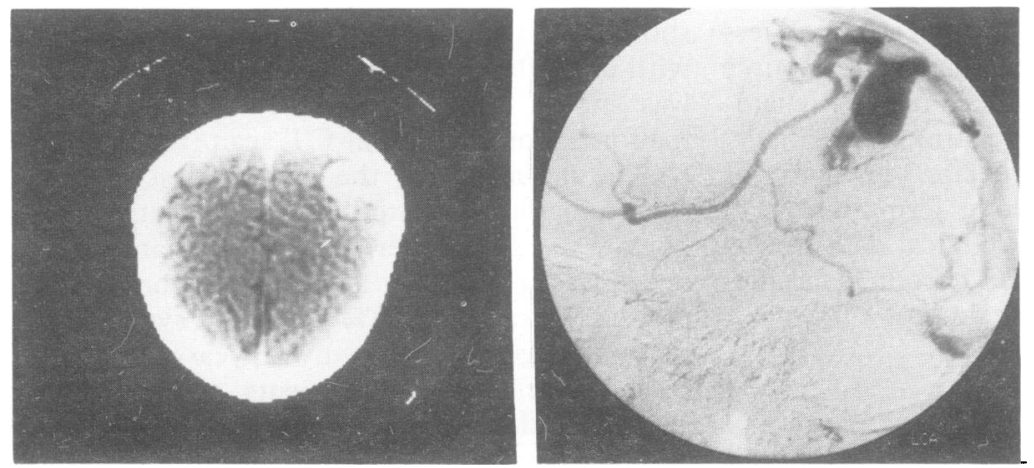

Figure 2 Cranial CT scan and angiogram showing cerebral AVM.

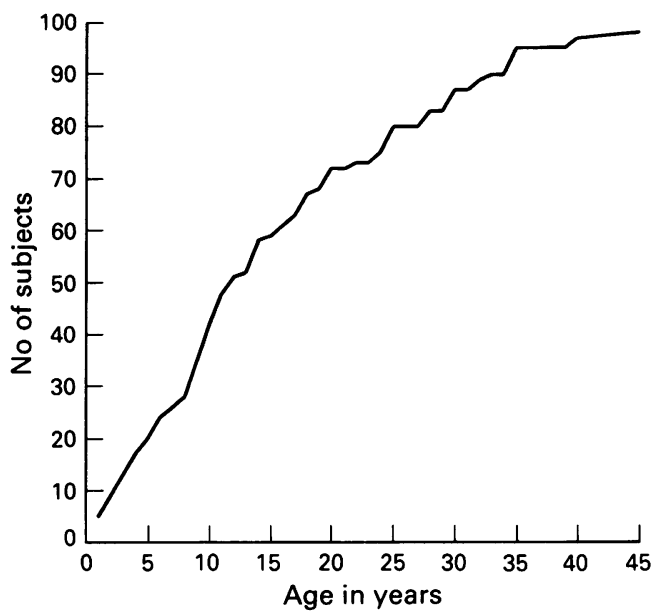

Figure 3 Age of onset of first symptoms of HHT plotted against cumulative frequency.

\section{Gastrointestinal bleeding}

Gastrointestinal bleeding was present in 16 patients. Lesions tended to be in the upper GI tract and stomach although this may reflect the fact that predominantly upper GI tract imaging was used to investigate these patients. Of the patients with GI bleeding, eight required blood transfusions to maintain their haemoglobin level.

\section{Pulmonary arteriovenous malformations}

Thirteen of the 56 patients in our series who had been $x$ rayed had a PAVM visible on chest radiograph. Of these, seven were symptomatic. Four patients developed embolic complications, three cerebral abscess, and one stroke. One patient aged 17 when seen had been shown to have a PAVM on chest radiograph at the age of 5 years. As he was asymptomatic at that time his parents decided against surgical correction. Twelve years later he was cyanosed and clubbed with severely limited exercise tolerance. Cardiac catheterisation showed a shunt at the level of the PAVM of approximately $50 \%$ of cardiac output (fig $5 \mathrm{~A}$ ). Surgical resection of the apical segment of the right lower lobe resulted in resolution of his symptoms (fig 5B).

\section{Cerebral involvement}

Much of the neurological morbidity of HHT is the result of embolic complications of pulmon-

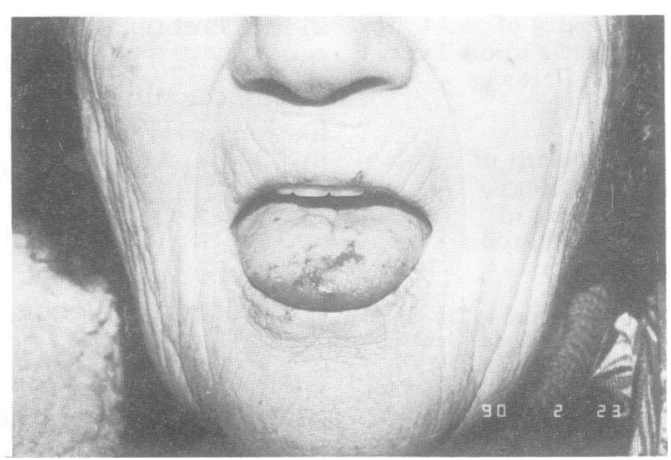

Figure 4 Telangiectases of the lips and tongue. 

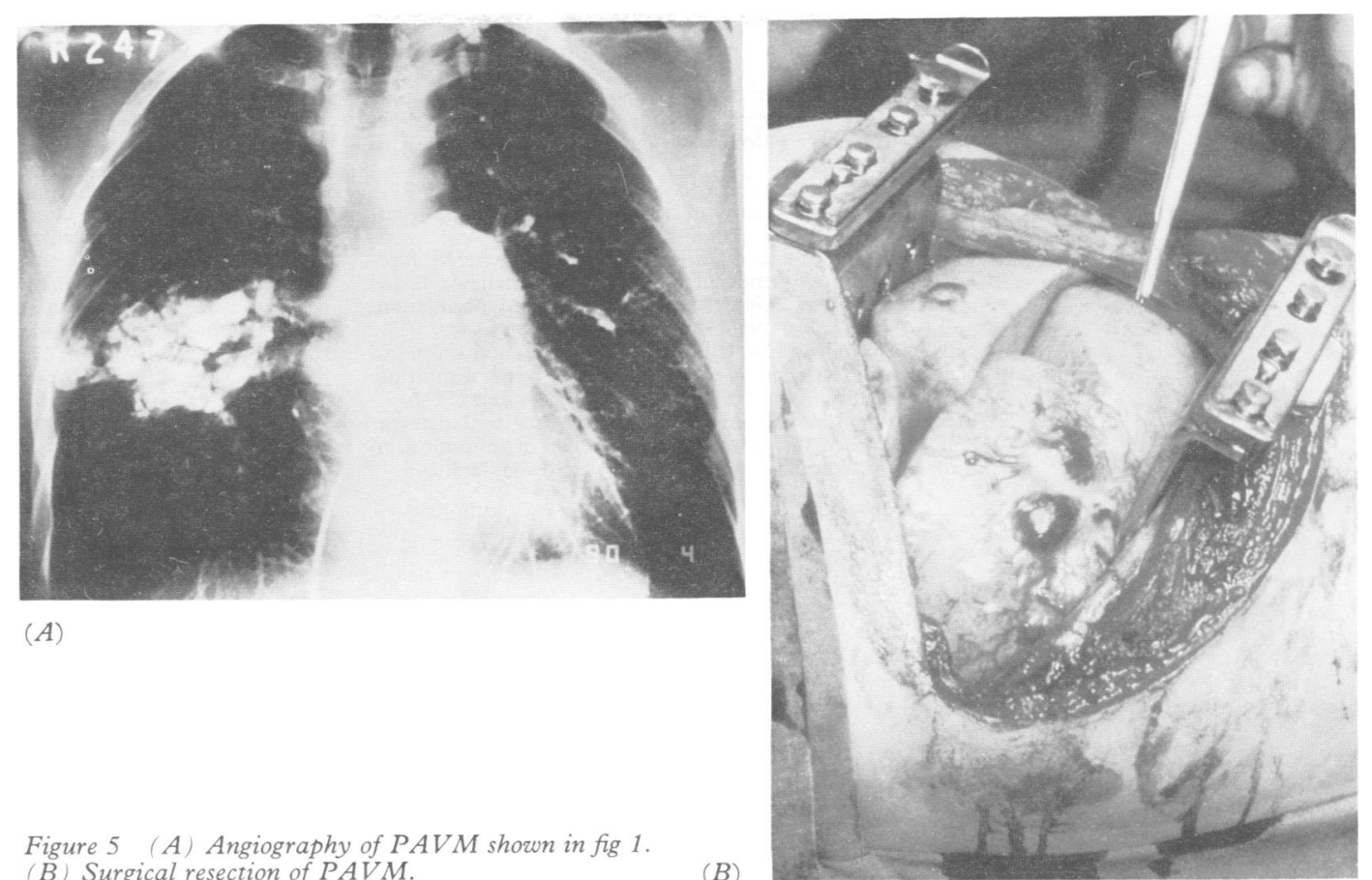

Figure 5 (A) Angiography of $P A V M$ shown in fig 1 .

(B) Surgical resection of $P A V M$.

$(B)$

ary arteriovenous malformations. ${ }^{13}$ Three patients had symptomatic cerebral arteriovenous malformations; $46.3 \%$ of patients with no known CNS pathology described visual symptoms suggestive of migrainous aura in the absence of headache and nausea compared with $5.7 \%$ of controls (manuscript in preparation).

\section{Discussion}

In 1989, Plauchu et al ${ }^{9}$ reported a prevalence of HHT in France of 1 in 8345, considerably higher than the previously accepted estimate of 1 in $100000 . .^{14}$ In the 103 three generation pedigrees there were three cases of apparent non-penetrance, suggesting a penetrance of $97 \%$. The present estimate of $1: 39216$ is the first prevalence estimate in a British population and is, almost certainly, an underestimate.

One weakness of the clinical study is that frequently, on domiciliary visits, only a limited examination of the skin is possible. However, full body examination of a limited number of cases indicates that cutaneous features are largely confined to the face, hands, and oronasal mucous membranes.

HHT is a very variable disorder which, although no more than a minor inconvenience to some patients, has devastating results in others. In common with other authors, we have found that most of the serious pathology associated with this condition is the result of pulmonary involvement. The three patients with cerebral abscess secondary to septic emboli all had asymptomatic pulmonary AVMs.

Specialised centres now offer transcutaneous balloon embolisation of pulmonary AVMs and it is hoped that early treatment will prevent embolic complications. ${ }^{15}$ Screening for pulmonary AVMs should be offered to all first degree relatives of patients with HHT. In our centre this consists of transcutaneous oxygen saturation measurements erect and supine and before and after moderate exercise together with a chest $x$ ray. Any alteration in oxygen saturation merits further investigation of the pulmonary vasculature.

The age of onset curve can be used in genetic risk calculations. We have found that family members are usually correct in their assessment of disease status in relatives. Where possible, nasal cautery should be avoided as its results are usually short term and may lead to further mucosal damage. Initial results with the $\mathrm{Nd}$ YAG laser are promising, ${ }^{16}$ but this treatment is not yet widely available in the UK.

The clinical geneticist has an important role to play in family tracing if adequate screening of subjects at risk is to be offered. We found two teenage patients with HHT and pulmonary AVMs who, despite being members of families well known to the local hospital, were not under follow up. One has since had an open resection while the other has been referred to a specialist cardiothoracic centre.

The pathological basis for HHT is unknown although it is likely to involve angiogenesis. As yet, no candidate genes have emerged and a total genomic search is under way for the locus. In addition to providing a means to identify presymptomatic gene carriers, the product of this gene will be of interest to those interested in the pathophysiology of new vessel growth.

1 Hanes FM. Multiple hereditary telangiectasis causing hemorrhage (hereditary hemorrhagic telangiectasia). Bull fohns Hopkins Hosp 1909;20:63-73.

2 Sohns Hopkins Hosp 1909;20:63-73. and of degeneration of the vascular system. Med Mirror $1864 ; 1: 769$.

3 Rendu $M$. Epistaxis repetees chez un sujet porteur de petits angiomes cutanes et muquex. Bull Mem Soc Med Hop 1896;13:731

4 Osler W. On a family form of recurring epistaxis associated with multiple telangiectases of the skin and mucous membranes. Bull fohns Hopkins Hosp 1901;12:333-7.

5 Weber FP. Multiple hereditary developmental angiomata (telangiectases) of the skin and mucous membranes associated with recurring haemorrhages. Lancet 1907;ii:1602. 
6 Posner DP, Sampliner RE. Hereditary hemorrhagic telangiectasia in three black men. Am $\mathcal{f}$ Gastroenterol

7 Harding JA, Velchik MG. Pulmonary scintigraphy in a patient with multiple pulmonary arteriovenous malformations and pulmonary embolism. $f \mathrm{Nucl}$ Med 1985;26:151-4.

8 Bird RM, Hammarsten JF, Marshall RA, Robinson RR. A family reunion: a study of hereditary hemorrhagic telan-

9 Plauchu H, de Chadarevian JP, Bideau A, Robert JM. Agerelated clinical profile of hereditary hemorrhagic telangiectasia in an epidemiologically recruited population. Am f Med Genet 1989;32:291-7.

10 Snyder LH, Doan CA. Clinical and experimental studies in human inheritance: is the homozygous form of multiple telangiectasia lethal? $\mathcal{L}$ Lab Clin Med 1944;29:1211-6.

11 Stecker RH, Lake CF. Hereditary hemorrhagic telangiectasia; review of 102 cases and presentation of an innovation to septodermoplasty. Arch Otolaryngol 1965;82:522-6.
12 Vase P, Holm M, Arendrup H. Pulmonary arteriovenous fistulas in hereditary hemorrhagic telangiectasia. Acto Med Scand 1985;218:105-9.

13 Hewes RC, Auster M, White RI. Cerebral embolism - first manifestation of pulmonary arteriovenous malformation in patients with hereditary hemorrhagic telangiectasia. Cardiovasc Intervent Radiol 1985;8:151-5.

14 McKusick VA. Mendelian inheritance in man; catalogs of autosomal dominant, autosomal recessive, and $X$-linked phenotypes. Baltimore: Johns Hopkins University Press,

15 White RI, Lynch-Nyhan A, Terry P, et al. Pulmonary arteriovenous malformations: techniques and long-term outcome of embolotherapy. Radiology 1988;169:663-9.

16 Mehta AC, Livingston DR, Levine HL. Fiberoptic bronchoscope and Nd-YAG laser treatment of severe epistaxis from nasal hereditary hemorrhagic telangiectasia and hemangioma. Chest 1990;91:791-2. 